\title{
Modelling Customer Satisfaction for Business Services
}

\author{
Megha Virmani \\ India \\ Email: virmanimegha@gmail.com \\ Dr. Manoj Kumar Dash \\ India
}

Accepted: May 03, 2013 Published: June 06, 2013

Doi:10.5296/jsr.v4i2.3824 URL: http://dx.doi.org/10.5296/jsr.v4i2.3824

\begin{abstract}
Research in the area of business services, which include marketing research companies, advertising agencies and consulting firms, has concentrated on service quality, relationship quality, and overall customer satisfaction. In some of the best known models which connect these concepts, customer satisfaction is modelled as a function of customer expectations and perceived quality. Little research has been done, however, to explain the development of relationships between businesses and business services over time. Additionally, research in this area has been almost non-existent in the transition countries. Our study proposes a customer satisfaction model with an integrated time component to be tested on the transition country data. The relationship quality in our model is expected to be paramount for customer satisfaction, loyalty and the long-term success of business services.
\end{abstract}

\section{Introduction}

Customer satisfaction with business service can be defined with a customer's positive or negative feeling about the value of using a business service in a specific situation. This feeling can be a reaction to an immediate use situation or an overall reaction to a series of use situation experiences (Woodruff, Gardial, 1996). Satisfaction is therefore related to customer value. Customer value (or client's value) is a perception of what a customer wants to accomplish with a help of a service, in order to reach a desired goal. Woodruff et al. (1996) argue that customer value describes the nature of the relationship between the firm-customer and the service, while customer satisfaction represents a customer's reaction to the value received from the service.

Furthermore, value identifies which service dimensions are central for a firm-customer to reach desired goals and how these service dimensions are related to one another and to the firm. Satisfaction, however, captures the customer's response to a particular service - how the customer feels about the service received. While value gives the business service provider a direction, satisfaction gives a report card on how they are doing. Therefore, firm-customers may have value hierarchies before the purchase of service, whereas 
satisfaction offers a historical perspective. Furthermore, customer value is generic, while satisfaction judgements are specific to a particular service.

A comparison of customer value orientation versus customer satisfaction measurements may further reveal that value orientation considers all levels of the customer's interaction with a service, including attributes, consequences, and end states. The customer value orientation is a longer term and more stable orientation. It helps to interpret information on specific service attributes in a practical way. Most traditional customer satisfaction measures, however, are focused almost exclusively on getting information about attributes. A focus on attributes is more unstable, leads to marginal change and improvement, and has a historical orientation. In the absence of additional consequence level information it is often difficult to interpret. Most traditional customer satisfaction measurements are therefore limited by their service versus customer perspective and their orientation toward attributes rather than the whole value hierarchy.

A creation of value is a key to customer loyalty. Loyalty is best quantified by retention rate and/or share of purchase. It has several secondary effects, including:

- revenue growth as a result of repeat purchases and referrals,

- cost decline as a result of lower acquisition expenses and efficiency of serving experienced customers, and

- employee retention (Reichheld, 1993, 1996).

\section{Models of Customer Satisfaction and Loyalty to Business Services}

Research in the area of services marketing has concentrated on service quality (Berry, Zeithaml, Parasuraman, 1990; Bitner, 1990; Boulding at al., 1993; Cronin and Taylor, 1992; Devlin, Dong, 1994), relationship quality (Crosby et al., 1990; Crosby, Stephens, 1987; Dwyer et al., 1987), and overall customer satisfaction (Cronin, Taylor, 1992; Anderson, Sullivan, 1993; Cann, 1995; Singh, 1990, 1991). In some of the best known models which connect concepts of loyalty, customer satisfaction and customer value, customer satisfaction is modelled as a function of customer expectations and perceived quality (Fornell, 1992). Fornell endorses a view of customer satisfaction, loyalty and switching behaviour which can also be applied to business services. He argues that there are two important functions which deal with customer satisfaction:

Customer satisfaction $=\mathrm{f}($ expectation, perceived performance),

Loyalty $=\mathrm{f}$ (customer satisfaction, switching barriers, voice).

According to this model, satisfaction increases customer loyalty and decreases switching behaviour. Switching barriers - e.g. search costs, learning costs, emotional cost, in addition to risks on part of the buyer - make it costly for the consumer to switch to another supplier. In a later work Johnson et al. (1995) argue that customer satisfaction is a cumulative construct that is affected by market expectations and performance perceptions in any given period, and is also affected by past satisfaction from period to period. Also, Anderson and Sullivan (1993) specify satisfaction as a function of perceived quality and "disconfirmation" - the extent to which perceived quality fails to match prepurchase expectations. Expectations in their model do not directly affect satisfaction. 
The most dominant theory of customer satisfaction is the expectancy-disconfirmation model (Oliver, 1980). According to this theory, satisfaction outcomes are a function of perceived performance and perceived disconfirmation. Perceived disconfirmation depends on perceived performance and standard for comparison. Standards of comparison may include expectations, ideals, competitors, other service categories, marketer promises and industry norms. If perceived performance is significantly worse than the comparison standard (more than the customer is indifferent to), a customer will experience negative disconfirmation (service did not meet the comparison standard). It does not matter how the service provider believed the service was performed. It is especially important for managers of business services to recognise negative disconfirmation, as it presents the largest threat to customer loyalty, word-of-mouth recommendation, repeat purchases, and other desirable customer responses.

Most of the research we presented suggests a development process of the relationships between businesses and business services over time. However, little research has empirically examined a multi-stage buyer-seller relationship model. Bejou (1994) study provides some elements of the buyer-seller relationships in a multi-stage buyer-seller mode. Applied to insurance services, he suggests the constructs of encounter quality and relationship quality, integrating the social penetration theory and interpersonal relationships theories with marketing theories.

\section{A Proposed Conceptualisation (Conceptual Framework) and Operationalisation of Customer Satisfaction with Business Services (Advertising Agencies)}

Wackman et al. (1986) discuss phases in business relationships between firms and advertising agencies. A pre-relationship phase is the beginning of a relationship cycle. It proceeds through a development and a maintenance phase and terminates in a termination phase. In the pre-relationship phase, both the agency and the client are learning from each other. During the development phase, both sides have still high expectations about each other. In the maintenance phase a deeper relationship is formed and some successful campaigns are made. The termination phase is when both parties separate - sometimes peacefully, sometimes abruptly. They pointed several relationship factors crucial to maintaining a relationship during maintenance and development phases, including trust/respect, personnel turnover etc. A similar study was conducted in the Netherlands (Verbeke, 1989).

Our study proposes a significantly different conceptual framework for a multi-stage customer satisfaction model. The orientation of our model is to measure customer satisfaction in client/agency relationship from the client's perspective which can be of use to both parties (see Figure 1). The following constructs are suggested:

1. Encounter quality (client's value): expected service level on dimensions of reliability, timeliness, responsiveness and competence from the company's perspective at the time of encounter, before the agency performed the required service for the client (Devlin, Dong, 1994). Research in the area suggests preferences and expectations about agency's experience, media skills and creative skills (Henke, 1995), how the company 
acknowledges the reputation of the agency in the industry (work done for the same industry in the past, trade awards for some of their past work, Henke, 1995) and match between agency's and company's communication style (Bejou, 1994) as measures for encounter quality (see Table 1 for some of the suggested measures). Encounter quality is an exogenous latent variable to our model.

2. Relationship quality: perceived service level on the above dimensions of the client/agency relationship, based on some experiences with the agency work. Corresponding measures are perceived agency's performance comparing to alternatives available (Bejou, 1994), quality of relationship with agency's upper management, comparative level of agency's media and marketing skills performance, strategic planning capabilities (Henke, 1995) and match to prepurchase expectations (Anderson and Sullivan, 1993; see Table 1).

3. Customer satisfaction: a focal construct in the model; cumulative, abstract affective construct that describes the total client's experience with advertising service (Johnson, Fornell, 1991). Its measures include satisfaction with agency's expertise, media and marketing skills performance, proven track of results (Henke, 1995), distance from the ideal service and overall satisfaction with agency performance (Oliva et al., 1992; see Table 1).

4. Switching barriers: make it costly for the client to switch to another agency (or difficult or illegal). Measures include time costs, effort costs, perceived risk and habit (Fornell, 1992). This variable is an exogenous latent variable in the model.

5. Loyalty: feeling of affinity with the agency, more than behavioural consistency in assigning sequential projects to the same agency/same creative. Measures are repurchase intention (Bejou, 1994), length of time with the current agency, and a degree of preference over alternative agencies/creative. ${ }^{i}$

6. Dissolution tendency: the final step in the relationship, tendency to terminate the relationship and switch to another agency. Measures are the likelihood of termination in the next future, accumulated threshold of dissatisfaction (Oliva et al., 1992) and conflict level leading to dissolution (Henke, 1995). ${ }^{\text {ii }}$

A long-term buyer-seller relationship, in our case between business company-client and advertising agency, requires that buyer and seller has:

1. an effective encounter quality in the exploration stage,

2. quality relationship in the expansion stage,

3. Satisfaction and loyalty in the commitment stage. A relationship could end at any stage, once the client and/or agency feel that the attractiveness and rewards of their relationship are lower than those of the alternative relationships.

According to the model, the exploration stage begins with the initial encounter of the company and agency when the agency is pitching for the account. In the initial phase of the encounter, the company develops an opinion of the preferences of the seller based on his or her previous experiences. A project assigned to agency suggests that their relationship 
encounter has been effective for both.

In the expansion stage, the focus shifts from the client to the agency. The agency needs to be committed to the client and the relationship. Continuous communication, co-operation, conflict avoidance and adaptability to client's needs are examples of behaviours that the agency can exhibit to enhance the quality and expansion of the relationship.

The progression from the expansion stage to the commitment stage is an indication that the rewards of the present relationships are much higher than the rewards of alternative relationships.

The outcomes of relationships with high quality are high levels of client/agency satisfaction, low levels of complaining and client's loyalty to the agency. On the other hand, the consequence of low levels of quality, satisfaction and loyalty is a dissolution of the relationship and/or switching behaviour. Final step in our model is the dissolution of the relationship.

The aforementioned relationships are summarised in the following hypotheses:

- Hypothesis 1: Encounter quality (client value) precedes in time the relationship quality as well as customer satisfaction, loyalty and dissolution.

- Hypothesis 2: Paths in the model - from encounter quality over relationship quality, customer satisfaction, and loyalty to dissolution - follow from the time sequence of the constructs over the life-cycle of agency-client relationship.

- Hypothesis 3: Positive causal effects lead from relationship quality to customer satisfaction.

- Hypothesis 4: For dissolution tendency, negative causal effects follow from all previous steps in the relationship development.

- Hypothesis 5: No direct paths between encounter quality and loyalty are justified by the fact that loyalty is not a necessary step in the client/agency relationship development.

○ Hypothesis 6: Switching barriers influence loyalty and/or dissolution tendency.

- Hypothesis 7: Loyalty follows from customer satisfaction and indirectly from encounter quality and relationship quality (value).

- Hypothesis 8: Relationship quality has a negative causal effect on dissolution tendency. 
Following the Bagozzi holistic construal (1984), the conceptual meaning of our focal concept (loyalty) is to be obtained through specification of the antecedents (encounter quality, relationship quality, switching barriers) and the consequences (loyalty, dissolution tendency). According to the model, all paths except for the paths to dissolution tendency should be positive. Also, a path from switching barriers to loyalty should be positive.

For testing of the model in a real setting, a sample size of 150 is suggested. According to Anderson and Gerbing (1988), this size should be sufficient to obtain a converged and proper solution for models with three or more indicators per factor. Furthermore, additional considerations and possible development of the model could be seen in multi-sample examples, with expanding to other business services. There is a strong need to include informants from the agency besides the informants only from the client's side which we assumed in the present design. As we are dealing with organisational setting where decisions are made in teams, multiple informants is also one of the possibilities. ${ }^{\text {ii }}$

\section{Discussion}

The purpose of this paper is to propose a conceptualisation and operationalisation of customer value, satisfaction, and loyalty to business service in relationships between firms and advertising agencies. Moreover, the paper lays a theoretical foundation on which further inquires can be based.

A long-term relationship between business company-client and the advertising agency progresses through an exploration stage, expansion, commitment, and finally dissolution. It requires that both the buyer and the seller experience an effective encounter in the exploration stage, quality relationship in the expansion stage and satisfaction and loyalty in the commitment stage. According to the model, the exploration stage begins with the initial encounter of the company and agency when the agency is pitching for the account. The progression from the expansion stage to the commitment stage is an indication that the rewards of the present relationships are much higher than the rewards of alternative relationships. The outcomes of relationships with high quality are high levels of client/agency satisfaction, low levels of complaint and client's loyalty to the agency. On the other hand, low levels of quality, satisfaction and loyalty result in a dissolution of the relationship and/or switching behaviour. A relationship could end at any stage, once the client and/or agency feel that the attractiveness and rewards of their relationship are lower than those of the alternatives.

A conceptual framework of customer satisfaction for business services proposed here could serve as a basis for further empirical research and contribute to a more comprehensive understanding of customer satisfaction. The framework postulates that customer satisfaction is determined with encounter quality and relationship quality. Similarly, the concept of loyalty is determined with encounter quality and relationship quality. The relationship 
quality in our model is therefore expected to be paramount for customer satisfaction, loyalty and also the long term success of business services.

\section{Implications for Management}

The proposed model is trying to capture our understanding of relationships between focal constructs - customer satisfaction, value and loyalty. It is once again stressing the importance of customer retention and loyalty for strategic capabilities of advertising agencies and their clients. Customer satisfaction should lead to loyalty which is more than simply a repurchase behaviour. Loyalty is about retention, price inelasticity, lower transaction costs and referrals, is about long-term relations of clients and agencies. At present, there are more than one hundred and eighty advertising agencies in the transition country of Slovenia (Dosje MM, 1996). It is not known that any of these agencies would measure customer satisfaction of their clients in a systematic way. The relational dyads between client and agency should be interesting from the viewpoint of firms as well as advertising agencies. Firms need to develop ways of selecting an agency and evaluating its performance. An advertising agency needs to know how to improve its performance and how to maximise its client's value. Knowledge of a client's value delivery system can serve as a competitive advantage in the competitive market of advertising.

\section{Figure 1: Conceptual Framework of Customer Satisfaction with Business Services}

\section{Table 1:}

\section{Proposed Questionnaire}

Constructs:

\section{Encounter Quality:}

$\mathrm{x} 1$ : _ When selecting advertising agency, our company prefers highly experienced agency.

( 1 = strongly disagree, $7=$ strongly agree $)$

$\mathrm{x} 2$ :_W We expect from the agency - to be able to communicate their creative skills, be willing to help, offer personal attention, employ well trained, polite, confident staff, understand our needs, offer convenient appointments, be easy to contact - before we would consider selecting them.

$(1=$ strongly disagree, 7 = strongly agree $)$

x3:_Agency which we would consider has to be - well known in the industry, keep promises, be on time with projects, right first time, should respond promptly, should have error-free records. $(1=$ strongly disagree, $7=$ strongly agree $)$

\section{Relationship Quality:}

$\mathrm{y} 1$ :_What is the overall performance of the agency comparing to other agencies?

$(1=$ much worse, $5=$ much better $)$

y2:_Compare to other advertising agencies the following elements of the current agency's performance: media skills, creative skills, marketing skills, strategic planning capabilities, winning numerous awards. $(1=$ much worse, $7=$ much better $)$ 
y3:_To what degree has the relationship with advertising agency met your original expectations? $(1=$ not at all, $7=$ very much $)$

\section{Customer Satisfaction:}

y4:_To what degree are you satisfied with the relationship that you have with this agency?

( 1 = not satisfied at all, $7=$ extremely satisfied $)$

y5:_Rate satisfaction with the current agency on the following performance variables (on a scale $1=$ not doing a good job at all, to $5=$ doing an excellent job): proven track record of results, agency experience, creative skills, media skills, marketing skills.

y6:_In terms of overall performance, how does this agency compare to your ideal? $(1=$ far from ideal, 7 = close to ideal)

\section{Switching Barriers:}

$\mathrm{x} 4$ :__ It would be too costly for the company to consider another agency at this moment.

$(1=$ strongly disagree, 7 = strongly agree $)$

$\mathrm{x} 5$ :__ I do not have the necessary time to reconsider our selection of the advertising agency at the moment. $(1=$ strongly disagree, 7 = strongly agree $)$

$\mathrm{x} 6$ :__Our company has been used to working with this agency.

$(1=$ strongly disagree, 7 = strongly agree $)$

\section{Loyalty:}

y7:_ It is likely that we will contract another project with this agency.

( 1 = strongly disagree, 7 = strongly agree $)$

y8:_A much superior alternative must be available before we would consider switching this agency. $(1=$ strongly disagree, $7=$ strongly agree $)$

y9:_We will continue to deal with this agency even if it is not the most price effective among its competitors. $(1=$ strongly disagree, $7=$ strongly agree $)$

\section{Dissolution Tendency:}

y10_We are considering looking for another agency.

( 1 = strongly disagree, 7 = strongly agree $)$

y11__Due to the conflict with this agency our company plans to terminate the relationship with this agency. ( 1 = strongly disagree, $7=$ strongly agree $)$

y12_What is the likelihood that you terminate your relationship with this agency with the next project? (1= not very likely, 7 = very likely)

\footnotetext{
${ }^{\mathrm{i}}$ Most advertising agencies experience high turnover of their creative people, and they make a point of rotating people through various accounts. They also experience constant client change accompanied by massive layoffs and severe downturns in revenues and profits. At Leo Burnett, in contrast, new staffers are assigned to their first accounts "for life". The company's strong positions in the advertising industry is largely attributable to its slavish devotion to employee retention (Reichfeld, 1993).

ii In several suggested measures above we agree with Henke (1995) who studied key predictors of an agency switch, using
} 
a longitudinal analysis of the client/agency relationship. The list includes dissatisfaction with the size of the company's account relative to the agency other accounts, dissatisfaction with the agency media skills and lower awareness of existing ad agencies. Creative skills of the agency and its ability to win awards were less important for companies that switched agencies. The author argues that the findings suggest the existence of distinct changes in the development of the agency-client relationship. The initial focus on creative skills which might have attracted the client at the beginning, shifts toward a performance focus later on (agency's ability to get results for the company, not for clients in general).

iii Additional issue to consider in a case of further development of a measurement model is that in marketing models, constructs can often be defined as linear functions of their indicators, called causal indicators, plus an error term. Such constructs are composite variables with no indicators in the conventional sense. Although the presence of composite variables could result in problems with identification of model parameters, some solutions exist (e.g. causal indicators as exogenous manifest variables and correlated with any exogenous latent variables, see MacCallum, Browne, 1993).

\section{References}

1. Anderson Eugene W., Sullivan Mary W. (1993): The Antecedents and Consequences of Customer Satisfaction for Firms. Marketing Science, Vol. 12, No. 2, Spring 1993, 125- 142.

2. Anderson James, Gerbing James(1988): Structural Equation Modeling in Practice: A Review and Recommended Two Step Approach. Psychological Bulletin, Vol. 103, No.3, 411-423.

3. Bagozzi (1984): A Prospectus for Theory Construction in Marketing. Journal of Marketing. Vol. 48, 11-29.

4. Bejou David (1994): Relationship-Selling Trajectories: A Conceptual Model and Empirical Investigation. Ph.D. Memphis State University, pp. 213.

5. Berry Leonard L., Zeithaml Valarie A., Parasuraman A. (1990): Five Imperatives for Improving Service Quality. Sloan Management Review. 31(4): 29-38. Summer.

6. Bitner Mary Jo (1990) : Evaluating Service Encounters: The Effects of Physical Surroundings and Employee Responses. Journal of Marketing. 54(2): 69-82.

7. Boulding William, Kalra Ajay, Staelin Richard, Zeithaml Valarie A.(1993) : A dynamic process model of service quality: From expectations to behavioral intentions. Journal of Marketing Research. 30(1): 7-27.

8. Cann Cynthia Winters (1995) : An Examination of Business to business Customer Satisfaction: The Depth of Use/Integration of High Technology Products (Industrial Marketing). Ph.D., State University of New York at Binghamton, pp. 234.

9. Cronin J. Joseph Jr., Taylor Steven A. (1992) : Measuring Service Quality: A Reexamination and Extension. Journal of Marketing. 56(3): 55-68.

10. Crosby Lawrence, Stephens Nancy (1987): Effects of Relationship Marketing on Satisfaction, Retention, and Prices in the Life of Insurance Industry. Journal of Marketing research. 24(4): 404-411.

11. Crosby Lawrence A., Evans Kenneth R., Cowles Deborah (1990): Relationship Quality in Services Selling: An Interpersonal Influence Perspective. Journal of Marketing. 54(3): 68-81. 
12. Devlin Susan J., Dong H.K. (1994): Service Quality From Customer's Perspective. Marketing Research. Vol. 6., No. 1, pp. 5-13.

13. Dwyer F. Robert, Schurr Paul H., Oh Sejo (1987): Developing Buyer-Seller Relationships. Journal of Marketing. 51(2): $11-27$.

14. Fornell Claes (1992): A National Customer Satisfaction Barometer: The Swedish Experience. Journal of Marketing. Vol. 56, 6-21.

15. Henke Lucy L. (1995): A Longitudinal Analysis of the Ad Agency-Client Relationship: Predictors of an Agency Switch. Journal of Advertising Research. March/April 1995. 24-30.

16. Johnson Michael D., Anderson Eugene W., Fornell Claes (1995): Rational and Adaptive Performance Expectations in a Customer Satisfaction Framework. Journal of Consumer Research. Vol. 21. 695-707.

17. MacCallum Robert C., Browne Michael W. (1993): The Use of Causal Indicators in Covariance Structure Models: Some Practical Issues. Psychological Bulletin. Vol. 114, No. 3, 533-541.

18. Dosje MM (1996), Marketing Magazin, Ljubljana, 66 p.

19. Oliva Terence A., Oliver Richard L., MacMillan Ian C. (1992): A Catastrophe Model for Developing Service Satisfaction Strategies. Journal of Marketing. 56(3): 83-95.

20. Oliver Richard L. (1980): A Cognitive Model of the Antecedents and Consequences of Satisfaction Decisions. Journal of Marketing Research, 17, pp. 460-469.

21. Reichheld Frederick F. (1996): Learning from Customer Defections. Harvard Business Review, March-April

22. Reichheld Frederick F. (1993): Loyalty-Based Management. Harvard Business Review, March-April 1993.

23. Singh Jagdip (1991): Understanding the Structure of Consumers' Satisfaction Evaluations of Service Delivery. Journal of the Academy of Marketing Science. 19(3): 223-244.

24. Singh, Jagdip (1990): Voice, Exit, and Negative word-of-mouth Behaviors: An Investigation Across Three Service Categories. Journal of the Academy of Marketing Science. 18(1): 1-15.

25. Verbeke (1989): Developing an Advertising Agency-Client Relationship in the Netherlands. Journal of Advertising Research. December 1988/January 1989, 19-27.

26. Wackman Daniel B., Salmon Charles T., Salmon Carlyn C. (1986): Developing an Advertising Agency-Client Relationship. Journal of Advertising Research 26(6): 21-28.

27. Woodruff Robert B., Gardial Sarah (1996): Know your customer: new approaches to customer value and satisfaction. Blackwell Publishers, Inc. Cambridge, Massachusetts. 